Rechtsmedizin 2020 - 30:292-299

https://doi.org/10.1007/s00194-020-00412-1

Published online: 4 September 2020

(C) The Author(s) 2020

\author{
W. Schweitzer ${ }^{1}$ M. Thali ${ }^{1} \cdot$ E. Aldomar ${ }^{2} \cdot$ L. Ebert $^{1}$ \\ 'Institut für Rechtsmedizin, Campus Irchel, Universität Zürich, Zurich, Switzerland \\ ${ }^{2}$ Department of Knowledge Visualization, ZHdK Zurich University of the Arts, Zurich, Switzerland
}

\title{
Overview of the use of 3D printing in forensic medicine
}

The use of PLA enables particularly fast $3 \mathrm{D}$ printing and the material may be relatively cheap [12]; however, 3D printing is not restricted to that. Other methods contain photopolymerization (whereas a liquid resin is hardened by exposure to light), material jetting (where the photosensitive material may be added as droplets into the print bed before ultraviolet light is applied to harden the material), binder jetting, sheet lamination, directed energy deposition, and powder bed fusion [29]. Thus, the term additive manufacturing has been used for $3 \mathrm{D}$ printing.

A particular strength of this type of object creation lies in that a relatively fast and affordable method (such as PLA or ABS printing) can be used to "instantly" print any digital 3D model. Having such options on-site invites prototype testing, the creation of new objects or replacement parts, or $3 \mathrm{D}$ objects for a simple demonstration.

The term rapid prototyping has been used as another synonym for 3D printing, but it really designates a different process: when the designer has created a digital 3D model during development and improvement cycles, 3D printing enables relatively fast, relatively affordable and relatively precise production of one physical instance of the digital 3D model. That physical object then can be inspected, touched, fitted in position, or mounted in place, tested, and after a list of deficiencies relevant to the final use of that object has been made, its digital3D model may be improved, and 3D printed again. Objects often require many cycles of improvement with prototype testing before a digital 3D model can be declared to be final. Using affordable rapidly available plastic models to see, test, and improve the shapes and dimensions of objects is extremely helpful, although that does not mean the finalversion gets to be produced the same way.

Conversely, the choice about the final form of a digital 3D model can be separated from the rapid prototyping phase. It may have to be decided on an individual basis whether the prototypes that were acceptable for testing are also fine for a final version, or whether a different type of manufacturing process may have to be used [6]. Once the development is finished, the same 3D model may be sent for a more elaborate fabrication; instead of plastic, a binder-jetting fabrication to generate metal objects, or laser sintering to achieve high definition acrylic objects, may be chosen [44].

\section{Description of the technique and steps}

\section{General object creation and manufacturing}

Manufacturing an object generally can be approached through various methods, including sheet metal processing, casting, and moulding, machining, manually shaping or carving using a range of materials including clay and last but not the least, 3D printing. Of these, some methods, including $3 \mathrm{D}$ printing, require that previously a digital 3D model of the object is made $[8,36]$.

\section{Creating a digital 3D model}

When an object's surface has to be digitally defined before manufacturing can be addressed, that surface has to enclose 


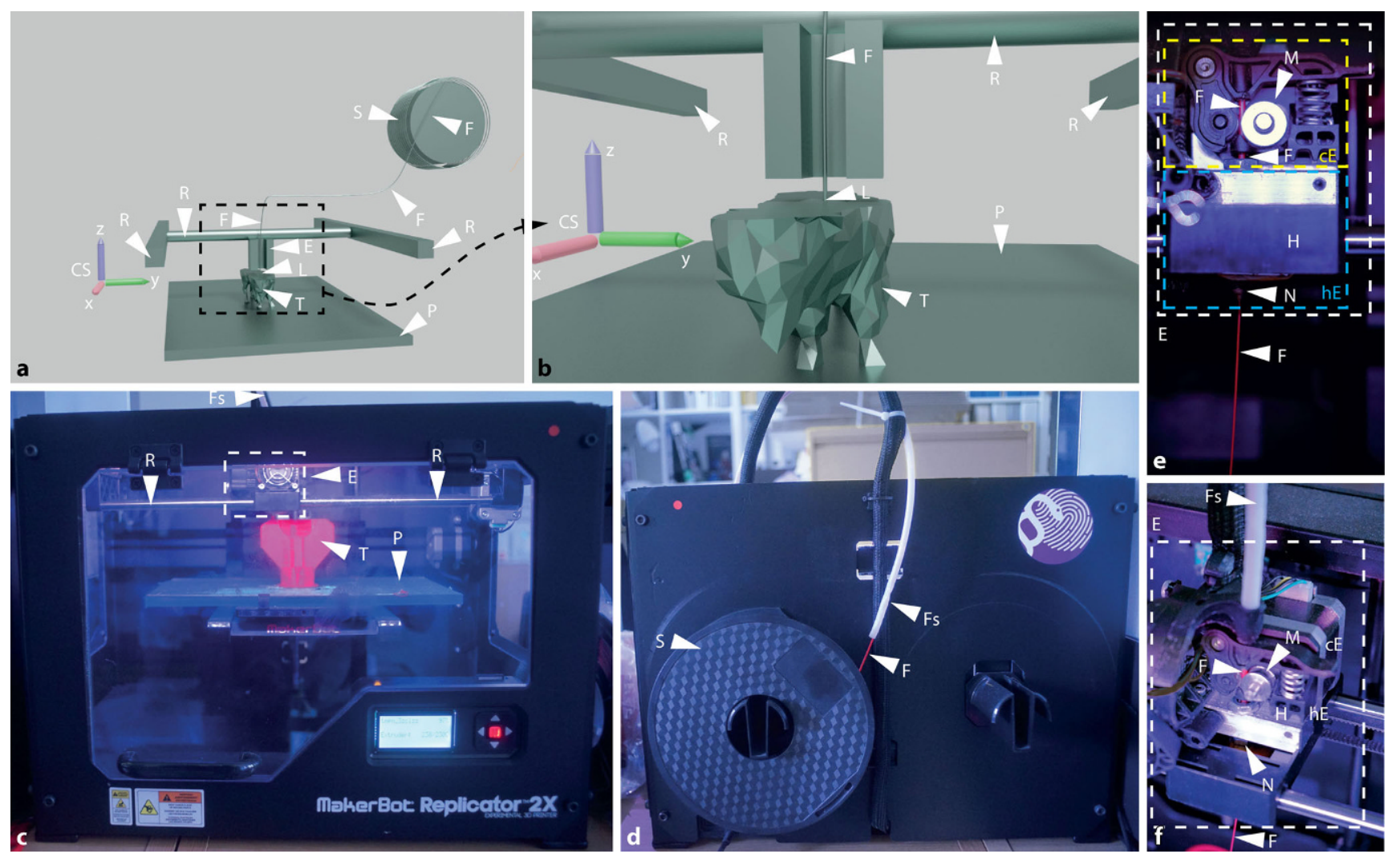

Fig. $1 \Delta$ Explanation of the function of a PLA-based 3D printer (also consider the coordinate system (CS) in images a and b). Flexible PLA filament of an even diameter ( $F$ ), typically sold on a roll and mounted on a spool $(S)$, is routed to the extruder $(E)$ of the 3D printer via a sheath $(F s)$. The extruder typically contains a cold end $(C E)$ and a hot end $(h E)$. In the cold end, there is a motor $(M)$ to pull the unheated and thus still solid filament to feed it into the hot end. The filament will lose its stiffness when melted so it can only be successfully transported by the motor as long as it is still solid. The hot end contains parts to generate, control and transmitheat $(H)$ that and only there, aims to melt the PLA, which then is extruded through a nozzle $(N)$. At this exact location $(L)$, the liquid PLA is added to what is under the nozzle which is located immediately above $L$ in any well calibrated 3D-printer. When the print process is started, the first layers of PLA will be placed directly onto the build plate $(P)$, which is later lowered (and thus moved in the direction of $-Z$ ), so the model $(T)$ is built incrementally. Subsequently, more PLA layers will be added onto the top surface of the model as it is being built (see also - Fig. 3, images a-c). A new layer can only be added once the previously deposited PLA has sufficiently cooled and hardened. Therefore, if one prints too fast, warping may occur. To reach across the area of the build plate, the extruder is moved along rails $(R)$ in the directions of $X$ and $Y$. Images $\mathbf{a}$ and $\mathbf{b}$ are symbolic images to illustrate the technical function of our PLA-based 3D printer. Images $\mathbf{c}$ and $\mathbf{d}$ show our 3D printer that was also used to print the model shown in - Fig. 3. That device had been initially set up with dual ABS extruders, but then was modified with an experimental PLA extruder $(E)$. Images $e$ and $f$ expose the inner details of our experimental extruder $(E)$ after we had removed the fan used for temperature control to take these photographs

a volume in such a way that the surface defines a so-called solid [14].

The two major ways of creating a 3D model are by capturing the surface of an existing real object (possibly by use of 3D scanning or photogrammetry) or by manually creating the $3 \mathrm{D}$ model using software [43]. These can be combined in that one may first obtain a 3D surface capture of an existing real object, and then use the resulting $3 \mathrm{D}$ model for further digital editing.

The use of 3D surface capturing may yield digital 3D models that are too large, too jagged, or noisy. Typically, edit- ing also to correct non-manifolds and to achieve solid geometry is required $[2,11]$. Not all surface angles may lend themselves to $3 \mathrm{D}$ surface capturing, therefore computed tomography (CT) scanning has been used to start off 3D model creation, in part with similar issues [11, 24]. Interestingly, some digital 3D models were edited not so much for technical reasons but to achieve a more convincing visual realism, such as by smoothing [11].

When using software to create $3 \mathrm{D}$ models, parametric (rather than freeform modeling) 3D software is an op- tion that may allow the user to go back to the digital 3D model and change the shape, design, size, position or orientation of parts with greater ease to improve the object [9].

Another advantage of using digital 3D models for object creation, rather than directly building physical models is that finite element modeling can be used to investigate mechanical properties of a given 3D model, or to compare some physical properties of the real object with virtual object properties. Resulting design modifications may be achieved faster using finite element modeling than by con- 
ventional physical testing, particularly if a single $3 \mathrm{D}$ print requires a lot of time and material to build [5].

\section{Material considerations and testing aspects}

The mechanical strength of additive manufacturing produced or 3D printed PLA or ABS models maybe summarized as relatively limited, subject to influences such as moisture, and as providing anisotropic mechanical properties $[12,22,23]$. Mechanical anisotropy means that the object tends to break easier along its build layers than perpendicularly to them (up to around $50 \%$ difference in directional stability [12]) and it is most marked in FDM processes. Overhangs may need the use of support structures for successful $3 \mathrm{D}$ printing, and hollow voids may be difficult to achieve [12].

Such aspects are not to be regarded as fixed but under continuous improvement. Generally, the surface of such a 3D printed object is defined by a deliberate number of shells containing a defined thickness, its inner volume is filled with any pattern and density of what is termed infill. Mechanical stability of a 3D print may thus be improved by using specific infills [26]. Also, PLA is continuously improved concerning its mechanical stability, for example by incorporating carbon fiber [16]. Surfaces may be smoothed using chemicals [4]. Whether the inherent mechanical anisotropy is a practical problem, whether it can be addressed by different digital 3D model orientation relative to the print bed and layering coordinates, may have to be decided on an individual basis or addressed by using building rules [1].

Testing the didactic or explanatory value of any $3 \mathrm{D}$ printed rendition over presentations in a flat shape (as on paper) does not appear to be straightforward and may have to engage in a dialogue with the subjects [32].

Testing 3D models and 3D printed objects may require both numerical modeling and experimental testing $[5,16,23]$. In forensic medicine, material behavior with respect to fluids, microbes or repetitive strain may be relevant.

Rechtsmedizin 2020 · 30:292-299 https://doi.org/10.1007/s00194-020-00412-1

(c) The Author(s) 2020

\section{W. Schweitzer · M. Thali · E. Aldomar · L. Ebert \\ Overview of the use of $3 \mathrm{D}$ printing in forensic medicine}

\section{Abstract}

In forensic medicine the use of so-called $3 \mathrm{D}$ printing is a niche application, whereas developments elsewhere in this field are rapidly advancing worldwide. The most common and widespread technology is fusion deposit modelling with polylactic acids (PLA). Although the equipment and materials may be relatively inexpensive and $3 \mathrm{D}$ printing relatively fast, the resulting end products tend to also have negative properties, such as poor durability and mechanical anisotropy, which may be an issue depending on the application. In forensic medicine, applications in the field of weapons technology and biomechanical models are realistic and 3D printing is already being used for demonstrations at court hearings and in teaching and also

\begin{abstract}
as a technique for building spare parts or accessories. Having a low-cost option for rapid prototyping on-site is particularly useful for the development phase. For finished $3 \mathrm{D}$ designs more expensive manufacturing options with a choice of materials with significantly broader mechanical or thermal properties are available. As the technology is undergoing major changes, one should carefully consider whether to enter the field oneself, buy own hardware, use a 3D printing service or seek cooperation possibly with a nearby partner.
\end{abstract}

Keywords

Teaching materials - Computed tomography . Engineering · Rapid prototyping · Computer simulations

\section{3-D-Druck in der Rechtsmedizin - eine Übersicht}

\section{Zusammenfassung}

In der Rechtsmedizin stellt die Verwendung des sog. 3-D-Drucks eine Nischenanwendung dar, wohingegen weltweit die Entwicklungen auf diesem Gebiet stark voranschreiten. Die am meisten verbreitete und gängigste Technologie ist die Schmelzschichtung mit Polymilchsäuren (PLA), wobei entsprechende Geräte und Materialien zwar relativ günstig sind und damit auch recht schnell gebaut werden können, die resultierenden Endprodukte aber je nach Anwendung negativ bewertete Eigenschaften, wie schlechte Haltbarkeit etwa bei Feuchtigkeit oder richtungsabhängig variable Festigkeiten, aufweisen. In der Rechtsmedizin erscheinen Anwendungen im Bereich Waffentechnik und biomechanische Modelle realistisch; bereits angewendet werden 3-D-Drucke für Demonstrationen an Gerichtsverhandlungen sowie in der Lehre, zudem als Technik für den
Bau von Ersatzteilen oder Zubehör. Dabei ist die kostengünstige Möglichkeit, Prototypen rasch zu bauen und zu testen, insbesondere für die Entwicklungsphase sinnvoll. Für die Fertigung von 3-D-Designs mit bedeutend breiteren mechanischen oder thermischen Eigenschaften stehen auch teurere Verfahren zur Verfügung. Indem die Technologie stark im Wandel ist, sollte man sich gut überlegen, ob man selbst einsteigt, zunächst auf eigene Hardware verzichtet und sich die Modelle über einen 3-D-Druckservice ausdrucken lässt, oder die Kooperation zu möglichst nahegelegenen vorhandenen Möglichkeiten sucht.

\section{Schlüsselwörter}

Lernmaterialien - Computertomographie - Konstruktion · Rapid Prototyping . Computersimulationen

\section{Application domains in forensic medicine}

\section{Medical teaching, demonstration, and diagnostics}

Medical imaging, including post-mortem computed tomography (PMCT) imaging, appears to be a great technical basis to $3 \mathrm{D}$ print anatomical models [27]. Such models may render pathology, foreign bodies such as projectiles, or injuries. The medical applications of 3D models for teaching in medicine as well as for surgery planning and implant definition are numerous [35]. One case of a comminuted skull fracture system identified the $3 \mathrm{D}$ printed documentation to exhibit great realism, particularly when compared to the autopsy finding [21]. 


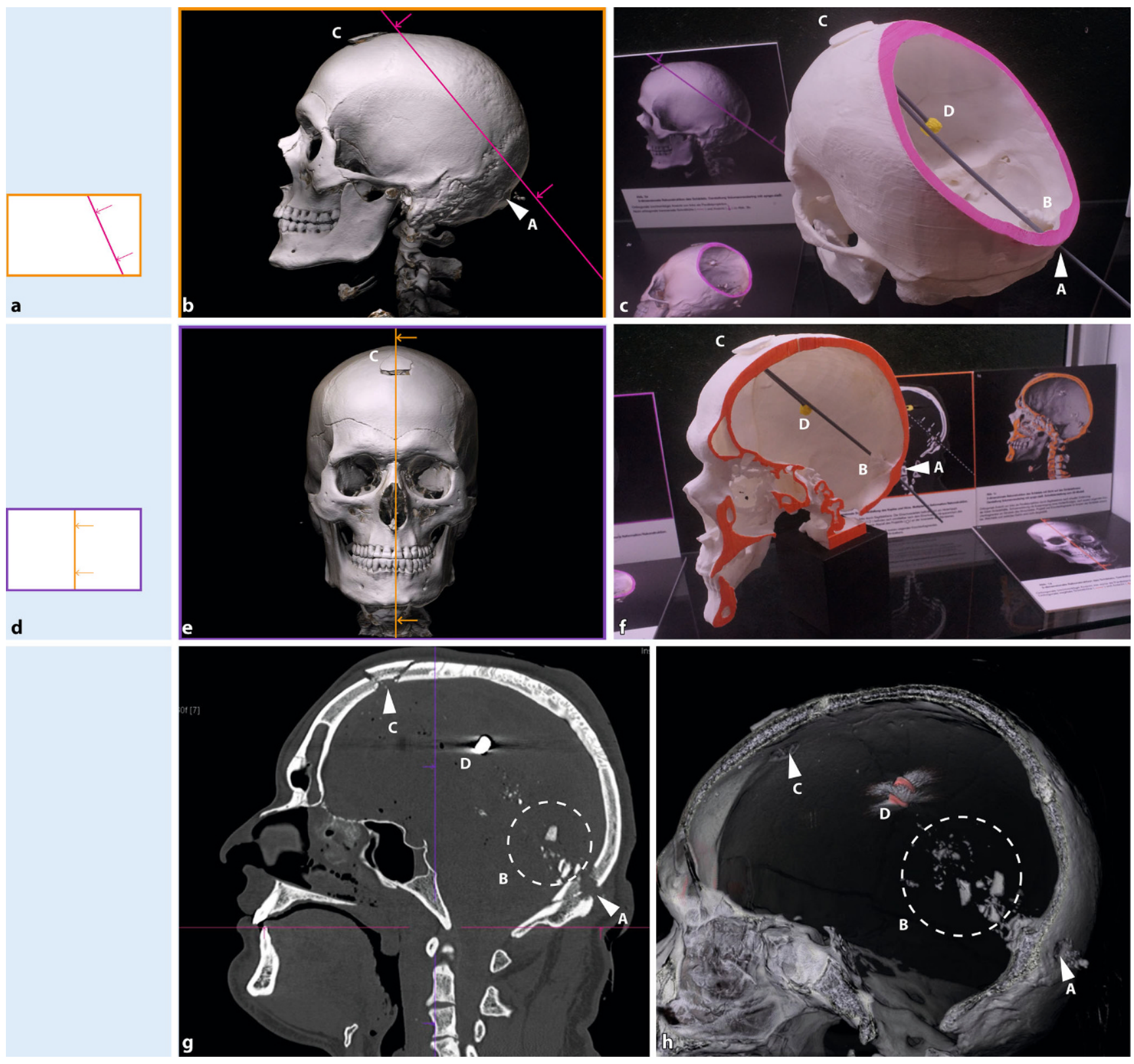

Fig. 2 A Injury visualization using 3D printing for didactic purposes, showing two 3D printed models of the same case. In this case of a gunshot to the back of the head (pistol, caliber $9 \mathrm{~mm}$ ), there was an occipital skull defect (entrance, $A$ ), and there were what appeared to be adjacent bone fragments inside the skull $(B)$. A round funnel-shaped fracture of the frontal bone close to the coronary suture was interpreted to indicate an internal ricochet $(C)$ with the final position of the projectile $(D)$ as shown in images $\mathbf{g}$ and $\mathbf{h}$. The skull was 3D printed twice $(\mathbf{c}, \mathbf{f})$, whereby the data had been prepared with an oblique occipitoparietal (a-c) and a sagittal section (d-f). The physical rendition of the 3D-printed correlate for the projectile ( $D$ in $\mathbf{c}$ and $f$ ) was mounted on a gray rod, that was used to also illustrate a possible trajectory. In conjunction with symbolic colors (schematic illustration of relative image orientations: $a$ and $d$; orthogonal views: $b$ and $e ; 3 D$ models: $c$ and $f$ ), the spatial configuration of reality and CT images can be explored

For diagnostic reasons, one study investigated the difference in the shape of 3Dprinted supratentorial brain magnetic resonance imaging (MRI) findings to help distinguish multiple sclerosis lesions from non-specific white matter changes [31]. In another application, faces were restored after replacing severely fractured facial and head bones with a $3 \mathrm{D}$ printed replica, to increase the diagnostic value of facial photography for identification and also to render the body more presentable to the bereaved [42].

The feasibility of generating such exhibits is easily demonstrated [11, 13]; however, it appears that reports on such models having actually been used in court are rare.

In one instance, head injuries of a 6year-old girl were presented in court as a 3D-printed model, while no further technical details of the $3 \mathrm{D}$ models were published [38]. 

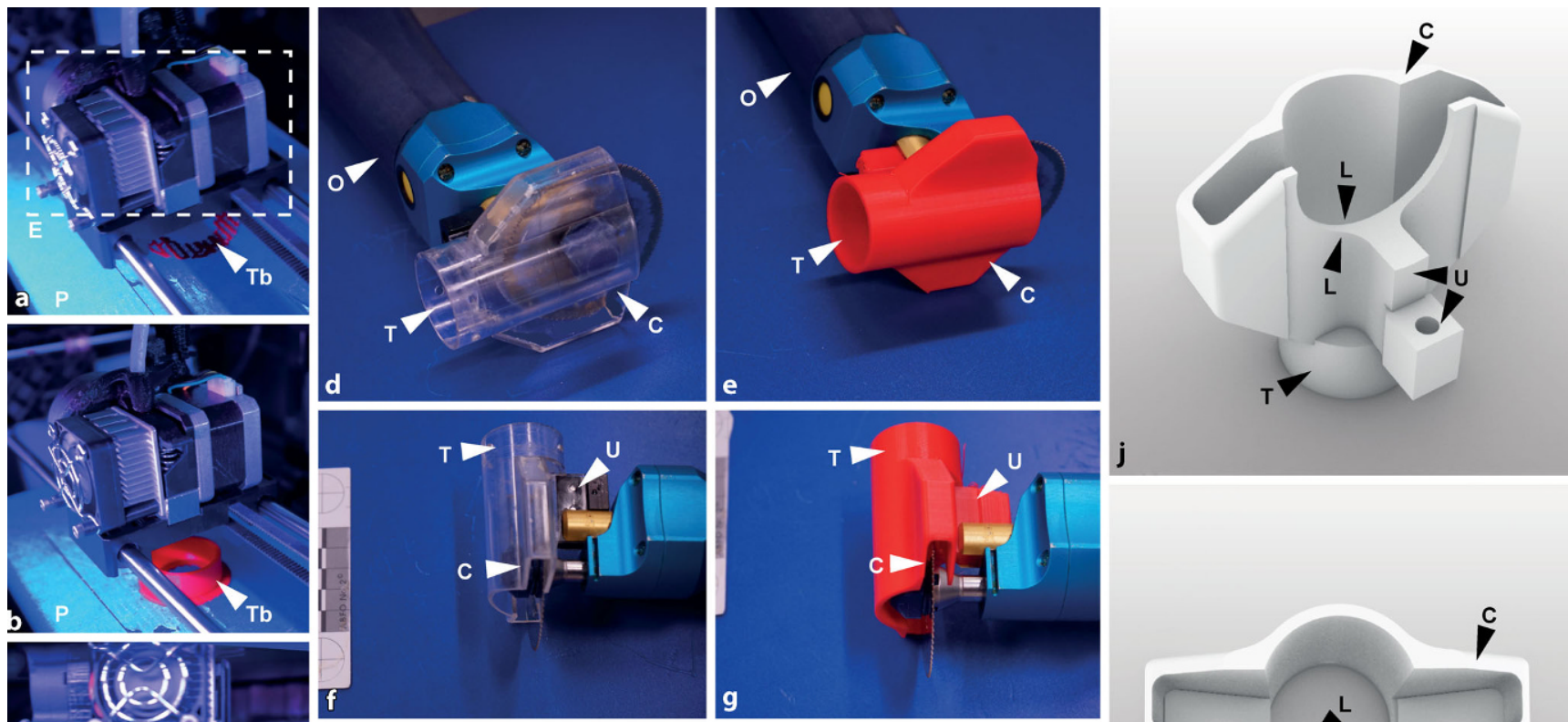

j
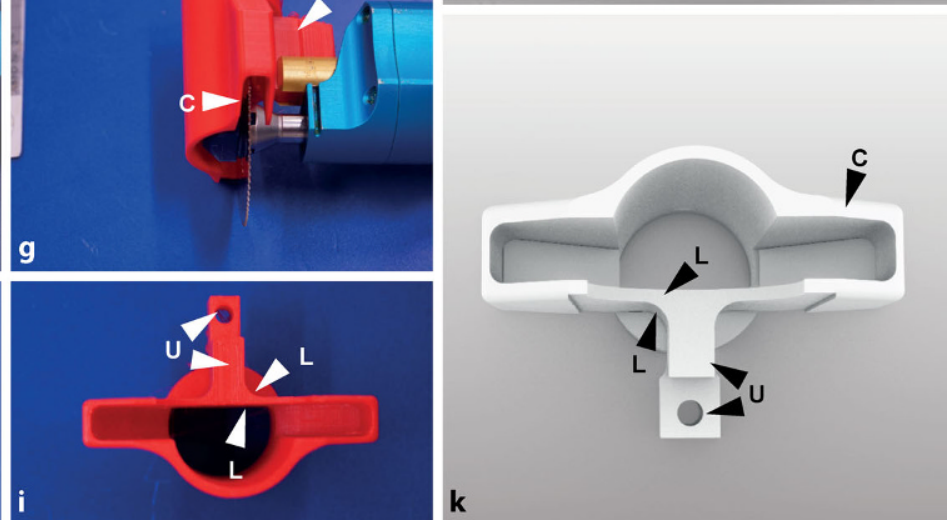

Fig. $3 \Delta$ Using 3D printing to design, test and develop replacement parts for an autopsy tool. We use an oscillating saw to cut bone, particularly to open skulls during autopsies $(0)$. This saw contains a plastic cover (transparent component in $\mathbf{d}, \mathbf{f}, \mathbf{h}$ ) that allows a suction hose to be attached to a round opening $(T)$, whereas the air stream then is flattened as an effect of the cover's shape that also partly encases the saw blade $(C)$. That plastic cover is mounted to the saw by a mount point $(U)$ that is inserted into a part of the saw and fixed to it with a screw. Our problem was that this plastic cover typically broke rather frequently, mostly between its mount point $(U)$ and the attached saw blade cover $(L)$. As a feasibility study, we built a prototype replacement part using the described methods of 3D-printing (red component in e, $\mathbf{g}$, i). Our design slightly differs from the original in that we employed filleted enhancements of the junction between the mount point $(U)$ and other parts (compare $L$ between images $h$ andi). This design adaptation was performed as a first approximation to reduce the frequency of this component's fractures. The prototype is currently shelved, it is pending further technical and use developments. Images a-c show the 3D-printing process of this part (extruder $E$, build plate $P$, model as it is being built $T b$ ). The first PLA layers of the model (Tb) getting attached to the build plate $(P)$ are shown in image $\mathbf{a}$. The incremental growth of the component is seen in images $\mathbf{b}$ (taken around $15 \mathrm{~min}$ after image $\mathbf{a}$ ) and $\mathbf{c}$ (taken around half an hour after image $\mathbf{b}$ ). The orientation of the digital 3D-model relative to the build plate is a key aspect that helps to determine whether the object can be 3D printed without or with less support structures

Anothervery interesting case was published by Baier et al. (2018) [3]. There, a complex skull fracture pattern had to be visually matched to tools used as possible weapons. Micro-CT based scans were used from which a stereolithography based 3D print using white resin (to approximate the color of natural bone) with a resolution exceeding the scan data was obtained. Practical advantages listed were the possibility for free unprotected handling and examination of the exhibit by the jury and the judge, without particular concern for anyone's safety.

We explored the use of $3 \mathrm{D}$ printing in the context of $3 \mathrm{D}$ visualization of injuries for didactic purposes. In our application, the case of a fatal head shot was visually rendered in various ways, including two different ways of detailing the findings as 3D print (• Fig. 2).

\section{Biomechanical models and weapons}

Biomechanical applications are another application where $3 \mathrm{D}$ printing is being used.

Biomechanical simulation of an infant's head to investigate head impacts contained a $3 \mathrm{D}$ printed skull model that approximated biofidelity through the use of two different materials on polyjet technology [20].

Temporal bone models used for surgical bone simulation were built using varying ratios of multiple thermoset polymers, to achieve unique mechanical properties of the different anatomical substructures contained in the temporal bone, including vasculature. There, the second model based on micro-CT outperformed the first one based on normal clinical CT data [34]. In this instance, the mechanical properties rather than visual appearance are the priority.

Investigating the performance of $3 \mathrm{D}$ printed continuously reinforced Kevlar 
on 3D-printed nylon composites showed that regardless of method details, a key finding was that the material architecture determined the performance against impact [39].

Weapons seem to be a rare application for $3 \mathrm{D}$ printing that one may still want to keep on the radar, but with little apparent practical impact so far. The Liberator is a partly $3 \mathrm{D}$ printed firearm that, when fired, also appears to widely spread polymer splinters across the scene $[18,19]$.

Last but not the least, projectiles were built using $3 \mathrm{D}$ printing. One task solved that way was the administration of extended-release contraceptives to animals by way of a customized 3D printed biodegradable projectiles. There, the contraceptive drug progesterone was admixed, in powder form, with PLA pellets [25].

\section{Tools and tool parts}

Building tool and application parts for use in forensic medicine is a further domain that lends itself to prototype development, testing, and object creation.

As new applications arise, such as post-mortem computed tomography angiography (PMCTA), we found that some required parts may not be commercially available, whereas others may be built with convenience, so we developed and built them in-house [37]. For these parts, up to around ten iterations were used to reach the current designs.

As a field, forensic medicine on occasion may make use of commercially available materials that appear to benefit from further adaptation as they could be viewed as cross-label use, such as the use of vibration saws [41] originally built for cast removal. We had experienced relatively frequent fracture damages to a particular location in a plastic addon for our oscillating autopsy bone saw. Therefore, over about four design iterations, we created a prototype for part replacement, whereas the weak area was reinforced (• Fig. 3).

In that domain, physical testing and documenting part performance and failure may be first main issues, at some stage also for documentation in the con- text of quality accreditation and control. On top, legal aspects such as copyright and patent or liability issues may have to be considered.

\section{Discussion}

The question whether one should acquire software and device operating skills or whether it is better to defer the tasks to others, may not be easy to answer. The technical requirements for both software and hardware aspects may be relatively challenging, so collaboration for $3 \mathrm{D}$ printing may have to be weighed carefully against setting up an own device or employing a 3D printing service [44]. One's own corporate or institutional setting that impacts prototype culture may play a considerable role in this, particularly as $3 \mathrm{D}$ printing is a method that seems fraught with procedural and conceptual issues, and where typical rapid prototyping cycles may easily exceed 20 or 50 cycle counts-a far cry from preceding methods such as clay modeling [36]. A more easily achieved but relevant suggestion however is to not run any of the 3D-printers on an institutional or corporate network, at least not permanently, because they may constitute a safety risk [30].

The justification of a courtroom use of 3D-printed plastic models of anatomical or medicolegal specimens in forensics may remain open to debate. After all, the attempt to deliver materials towards understanding a particular spatial configuration may be seen as constituting only a piece in a greater picture, a step towards a different goal. The art of explaining spatial relationships there may lie in avoiding distraction on that path and in giving sufficiently different angles. Questioning the value of $3 \mathrm{D}$ presentation is not restricted to forensic medicine: while moviemakers' attempts to use stereoscopy to protrude their content towards the viewers, that may be the exact style element to prevent them to be absorbed into a diegesis [17]. Conversely, a study found that a group of people of different legal and non-legal backgrounds preferred the 3Dprinted skull to photographs or printed images [7].
Using 3D printing to create new parts, components, or other structures to support practical work, often termed "things", has the potential to open new ways of performing examinations, or to improve existing products. There, it is our experience that sufficiently large iteration counts of the prototyping cycles are a key element.

With all that, it depends on where one wishes to go with developing 3D-models. Using 3D-printing to mass produce items once a final design has been reached may not be as sensible as shifting to different modes of production. A break-even analysis may be estimated across available options. According to one study, 3D printing (depending on specifics) may be only good up to around 200 units, whereas injection moulding scales better for higher volumes [15]. Conversely, if a design is changed and improved, like after every 50 units, or if the manufacturing process is scattered about geographically, or if $3 \mathrm{D}$ printing is crowd-sourced, the situation may look different [33]; however, so far the application of 3D printing inside the specific application domain of forensic medicine does not appear to be a largescale activity.

\section{Practical conclusion}

As it appears, 3D printing denotes a part of manufacturing that contains a range of techniques from digital 3D model creation over prototype testing to obtaining finalized products. The application in forensic medicine may be in generating anatomical models to exhibit pathology or trauma, to build tool parts or to generate biomechanical models. All of these are relatively new, however. The technical requirements for software and hardware aspects may be challenging, so using a 3D printing service instead, or seeking collaboration for 3D printing with a nearby facility may have to be weighed carefully against setting up an own device. As the development of the relevant software and the physical aspects of making physical objects, 3D-printing in a narrow sense, are currently ongoing, following these developments is certainly interesting. 


\section{Corresponding address}

\section{W. Schweitzer}

Institut für Rechtsmedizin, Campus Irchel, Universität Zürich

Winterthurerstrasse 190/52, 8057 Zurich, Switzerland

wolf.schweitzer@irm.uzh.ch

Acknowledgements. The authors express their gratitude to Emma Louise Kessler, MD for her generous donation to the Zurich Institute of Forensic Medicine, University of Zurich, Switzerland.

Funding. Open access funding provided by University of Zurich

\section{Compliance with ethical guidelines}

Conflict of interest. W. Schweitzer, M. Thali, E. Aldomar and $\mathrm{L}$. Ebert declare that they have no competing interests.

Ethical standards. Data use for publication in anonymized form was submitted to and considered by our local ethics committee, that then issued a nonobstet declaration (KEK Zurich, 15-0686).

Open Access. This article is licensed under a Creative Commons Attribution 4.0 International License, which permits use, sharing, adaptation, distribution and reproduction in any medium or format, as long as you give appropriate credit to the original author(s) and the source, provide a link to the Creative Commons licence, and indicate if changes were made. The images or other third party material in this article are included in the article's Creative Commons licence, unless indicated otherwise in a credit line to the material. If material is not included in the article's Creative Commons licence and your intended use is not permitted by statutory regulation or exceeds the permitted use, you will need to obtain permission directly from the copyright holder. To view a copy of this licence, visit http://creativecommons.org/licenses/by/4.0/.

\section{References}

1. Ahn SH, Montero M, Odell D, Roundy S, Wright PK (2002) Anisotropic material properties of fused deposition modeling ABS. Rapid Prototyp J 8(4):248-257. https://doi.org/10.1108/ 13552540210441166

2. Attene M, Campen M, Kobbelt L (2013) Polygon mesh repairing: an application perspective. ACM Comput Surv 45(2):1-33

3. Baier W, Warnett JM, Payne M, Williams MA (2018) Introducing 3D printed models as demonstrative evidence at criminal trials. J Forensic Sci 63(4):1298-1302

4. Baran EH, Erbil HY (2019) Surface modification of $3 \mathrm{D}$ printed pla objects by fused deposition modeling: a review. Colloids Interfaces 3(2):43

5. Bhandari S, Lopez-Anido R (2018) Finite element analysis of thermoplastic polymer extrusion 3D printed material for mechanical property prediction. Addit Manuf 22:187-196
6. Bikas H, Stavropoulos P, Chryssolouris G (2016) Additive manufacturing methods and modelling approaches: a critical review. Int J Adv Manuf Technol 83(1-4):389-405

7. Blau S, Phillips E, O'Donnell C, Markowsky G (2019) Evaluating the impact of different formats in the presentation of trauma evidence in court: a pilot study. Aust J Forensic Sci 51(6):695-704

8. Bralla JG (2006) Handbook of manufacturing processes. Industrial Press, New York

9. Camba JD, Contero M, Company P (2016) Parametric CAD modeling: an analysis of strategies for design reusability. Comput Aided Des 74:18-31

10. Cantrell JT, Rohde S, Damiani D, Gurnani R, DiSandro L, Anton J, Young A, Jerez A, Steinbach D, Kroese Cetal (2017) Experimental characterization of the mechanical properties of 3D-printed ABS and polycarbonate parts. Rapid Prototyp J 23(4):811-824. https://doi.org/10.1108/RPJ-032016-0042

11. Carew RM, Morgan RM, Rando C (2019) A preliminary investigation into the accuracy of 3D modeling and 3D printing in forensic anthropology evidence reconstruction. J Forensic Sci 64(2):342-352

12. Dizon JRC, Espera AH Jr, Chen Q, Advincula RC (2018) Mechanical characterization of 3D-printed polymers. Addit Manuf 20:44-67

13. Ebert LC, Thali MJ, Ross S (2011) Getting in touch $-3 \mathrm{D}$ printing in forensic imaging. Forensic Scilnt 211(1-3):e1-e6

14. Fisher $G$ (2013) Blender 3D printing essentials. Packt Publishing Ltd, London

15. Franchetti M, Kress C (2017) An economic analysis comparing the cost feasibility of replacing injection molding processes with emerging additive manufacturing techniques. Int J Adv Manuf Technol 88(9-12):2573-2579

16. Heidari-Rarani M, Rafiee-Afarani M, Zahedi A (2019) Mechanical characterization of FDM 3D printing of continuous carbon fiber reinforced PLA composites. Compos Part B Eng 175:107147

17. Higgins S (2012) 3D in depth: Coraline, Hugo, and a sustainable aesthetic. Film Hist Int J 24(2):196-209

18. Honsberger $H$, Rhumorbarbe $D$, Werner $D$, Riva $F$, Glardon M, Gallusser A, Delémont O (2018) How to recognize the traces left on a crime scene by a 3D-printed liberator? Part 1. Discharge, exterio ballistic and wounding potential. Forensic Sci Int 286:245-251

19. Honsberger $H$, Werner $D$, Rhumorbarbe $D$, Riva $F$, Glardon M, Gallusser A, Delémont O (2019) How to recognise the traces left on a crime scene by a 3Dprinted Liberator? Part 2. Elements of ammunition, marks on the weapons and polymer fragments. Forensic Sci Int 295:137-144

20. Jones M, Darwall D, Khalid G, Prabhu R, Kemp A, Arthurs OJ, Theobald P (2017) Development and validation of a physical model to investigate the biomechanics of infant head impact. Forensic Sci Int 276:111-119

21. Kettner $M$, Schmidt $P$, Potente $S$, Ramsthaler $F$, Schrodt M (2011) Reverse engineering - rapid prototyping of the skull in forensic trauma analysis. JForensic Sci 56(4): 1015-1017

22. KimE, Shin YJ, AhnSH (2016) The effects of moisture and temperature on the mechanical properties of additive manufacturing components: fused deposition modeling. Rapid Prototyp J 22(6):887-894 https://doi.org/10.1108/RPJ-08-2015-0095

23. Letcher T, Waytashek M (2014) Material property testing of 3D-printed specimen in PLA on an entrylevel 3D printer. In: 2014 ASME International
Mechanical Engineering Congress and Exposition American Society of Mechanical Engineers, Proceedings of 2014 ASME International Mechanical Engineering Congress and Expositio, Quebec, 14.11.-20.11. vol 46438, pp 1-8

24. Liacouras $P C$, Sahajwalla $D$, Beachler MD, Sleeman T, Ho VB, Lichtenberger JP (2017) Using computed tomography and $3 \mathrm{D}$ printing to construct custom prosthetics attachments and devices. 3d Print Med 3(1):8

25. Long J, Nand AV, Ray S, Mayhew S, White D, Bunt CR, Seyfoddin A (2018) Development of customised 3D printed biodegradable projectile foradministrating extended-release contraceptive to wildlife. Int JPharm 548(1):349-356

26. Lubombo C, Huneault MA (2018) Effect of infill patterns on the mechanical performance of lightweight 3D-printed cellular pla parts. Mater Today Commun 17:214-228

27. Marro A, Bandukwala T, Mak W (2016) Threedimensional printing and medical imaging: a review of the methods and applications. Curr Probl Diagn Radiol 45(1):2-9

28. Mitsouras D, Liacouras P, Imanzadeh A, GiannopouIos AA, Cai T, Kumamaru KK, George E, Wake N, Caterson EJ, Pomahac B et al (2015) Medical $3 \mathrm{D}$ printing for the radiologist. Radiographics 35(7):1965-1988

29. Mitsouras D, Liacouras PC (2017) 3D printing technologies. In: Rybicki FT, Grant GT (eds) 3D printing in medicine. Springer, Cham, pp 5-22

30. Moore S, Armstrong P, McDonald T, Yampolskiy M (2016) Vulnerability analysis of desktop 3D printer software. In: 2016 resilience week (RWS). IEEE, proceedings of a meeting Chicago, 16-18.08.2016, pp 46-51

31. Newton BD, Wright $K$, Winkler MD, Bovis $F$, Takahashi M, Dimitrov IE, Sormani MP, Pinho MC, Okuda DT (2017) Three-dimensional shape and surface features distinguish multiple sclerosis lesions from nonspecific white matter disease. JNeuroimaging 27(6):613-619

32. Pyle EJ (1998) The role of classroom artifacts in the clinical supervision of science. NASSP Bull 82(597):70-76

33. Rayna T, Striukova L (2014) The impact of 3D printing technologies on business model innovation. In: Digital enterprise Ddsign \& management. Springer, Berlin, pp 119-132

34. Rose AS, Kimbell JS, Webster CE, Harrysson OL, Formeister EJ, Buchman CA (2015) Multi-material 3D models for temporal bone surgical simulation. Ann Otol Rhinol Laryngol 124(7):528-536

35. Rybicki FT, Grant GT (2017)3D printing in medicine. Springer, Cham

36. Schrage M (1996)Cultures of prototyping. Bringing Design to Software 4(1):1-11

37. Schweitzer W, Enders M, Thali M (2019) Very affordable post mortem $\mathrm{CT}$ angiography kit: Feasibility study using immersion pump and 3D printed parts. J Forensic Radiol Imaging 16:11-18

38. Scott C (2013) 3D printed skulls presented as evidence in murder trial, in a first for the British legal system. 3Dprint.COM-Website. https:// 3dprint.com/133715/ellie-butler-murder-trial/. Accessed 10 July 2020

39. Scrocco M, Chamberlain T, Chow C, Weinreber L, Ellks E, Halford C, Cortes P, Conner BP, Incubator YB (2018) Impact testing of 3D printed kevlarreinforced onyx material. In: 2018 annual international solid freeform fabrication symposium - an additive manufacturing Conferenc Proceedings of the 29th Annual International Solid Freeform Fabrication, Austin, 13.08.-15.08., pp 1121-1144 
40. Song Y, Li Y, Song W, Yee K, Lee KY, Tagarielli VL (2017) Measurements of the mechanical response of unidirectional 3D-printed PLA. Mater Des 123:154-164

41. Torén K, Jonsson P (1996) Is skull sawing by autopsy assistants overlooked as a cause of vibrationinduced white fingers? Scand J Work Environ Health 22:227-229

42. Urbanová P, Vojtišek T, Frišhons J, Šandor O, Jurda M, Krajsa J (2018) Applying 3D prints to reconstructing postmortem craniofacial features damaged by devastating head injuries. Leg Med 33:48-52

43. Villa C, Flies MJ, Jacobsen C (2018) Forensic 3D documentation of bodies: Simple and fast procedure for combining ct scanning with external photogrammetry data. J Forensic Radiol Imaging 12:e2-e7

44. Wirth M, Thiesse F (2014) Shapeways and the 3D printing revolution. In: 2014 European Conference on Information Systems (ECIS) ECIS, Proceedings of the ECIS, Tel Aviv, 9.06.-11.06., pp 1-14

\section{Veranstaltungstipp}

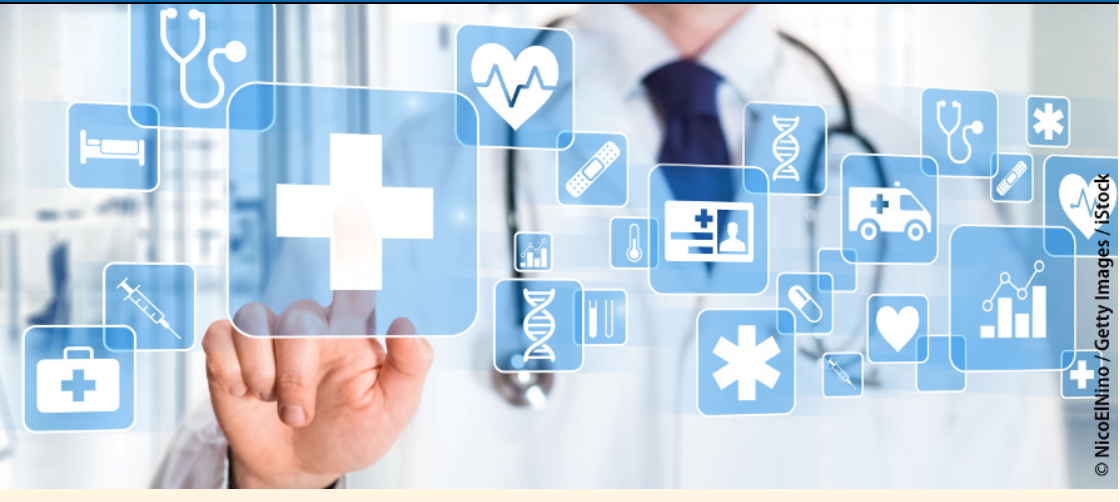

17. DGIV-Bundeskongress, 29. Oktober 2020

Überwindung der Sektorengrenzen - Erkenntnisse aus der CORONA-Krise

Die Deutsche Gesellschaft für Integrierte Versorgung e.V. ist ein deutschlandweit agierender Verein mit der Zielsetzung, die Integrierte Versorgung in der medizinischen, pflegerischen und sozialen Betreuung als Regelfall durchzusetzen und die dazu erforderliche Beseitigung der noch bestehenden strukturellen Hemmnisse zu befördern. Vor diesem Hintergrund lädt die DGIV zu ihrem Bundeskongress ein, der sich dem Themenkomplex CORONA (Lessons learned/ Resilienz) widmet.

\section{Lehren aus der CORONA-Krise für die} Integrierte Versorgung

- CORONA-Krise - Katalysator zur Überwindung der Sektorengrenzen

- Integrierte Versorgung - CORONA und danach

- Ethische Erkenntnisse aus der CORONAKrise

\section{Sektorenübergreifende Versorgung}

- Bewertung der Arbeitsergebnisse der Bund-Länder-Arbeitsgruppe sektorenübergreifende Versorgung

- Zu wenig Freiheit oder zu viele GruppenEgoismen? - Woran hakt es bei der Weiterentwicklung der integrierten Selektivversorgung?

- Wieviel „ambulant" können Krankenhäuser und wieviel "stationär" können Vertragsärzte leisten?
CORONA-Erfahrungen - die medizinische Perspektive

- CORONA-Erfahrungen aus erster Hand "Hotspot" Madrid

- CORONA-Erfahrungen aus der Hauptstadt Deutschlands - am Beispiel von Vivantes

- CORONA-Erfahrungen aus der Onkologie - wie sieht die Tumormedizin der Zukunft aus?

\section{Podiumsdiskussion „Wie sieht die} Roadmap nach CORONA aus?"

\section{Veranstalter}

DGIV e.V., Wartburgstraße 11, 10823 Berlin, Tel.: 030/44727080, Fax: 030/44729746,

E-Mail:info@dgiv.org

\section{Wissenschaftliche Leitung}

Prof. Dr. Stefan G. Spitzer, Dresden

Prof. Dr. Dr. Alfred Holzgreve, Berlin

Dr. Michael Meyer, Berlin

\section{Tagungsort}

Hotel Aquino, Tagungszentrum Katholische Akademie, Hannoversche Straße 5b, 10115 Berlin-Mitte

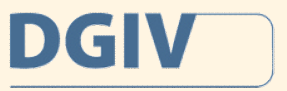

Deutsche Gesellschaft fuir Integrierte Versorgung im Gesundheitswesen e.

Quelle und weitere Infos: www.dgiv.org 